\title{
Premedical students' experiences in community-oriented primary care
}

\section{Eal Whan Park}

Department of Family Medicine and Division of Medical Education, Dankook University College of Medicine, Cheonan, Korea

\section{의예과 학생들의 지역사회중심 일차의료 실천 경험}

단국대학교 의과대학 가정의학과, 의학교육실

\section{박일환}

Purpose: Medical students must be taught community medicine to understand common community-wide health problems and develop the skills that are needed to solve them. In this study, community-oriented primary care (COPC) projects were undertaken by premedical students in a community medicine course, and their experience was assessed.

Methods: We analyzed the final reports of 570 premedical students who completed their community group projects from 2000 to 2012.

Results: Eighty-nine community projects were completed by the students. The average number of students per project was 6.3 (range, 3-9). The total number of project themes was 39. Sex education for high school students, guidance on learning for low socioeconomic children, and education on smoking cessation for high school students were the most frequently selected topics. The most common subjects in the projects were high school students, preschool children, elderly people, and hospice patients. With regard to methodology, the students administered questionnaires in 58 cases and held health education programs in 48 cases. In 42 cases, students used social welfare-related community resources. In their final reports, many students felt that an understanding of their identities as future physicians and of the health care and social welfare systems was meaningful.

Conclusion: Premedical students' experiences in COPC projects varied and were positive. Teaching community medicine in a premedical course increased students' confidence with their future role as compassionate, socially responsible physicians and their understanding of community resources in a health care network.

Key Words: Premedical students, Community medicine, Primary health care

Received: March 15, 2013 • Revised: May 3, 2013 • Accepted: June 27, 2013 Corresponding Author: Eal Whan Park

Department of Family Medicine and Division of Medical Education, Dankook University College of Medicine, 119 Dandae-ro, Dongnam-gu, Cheonan 330-714, Korea

Tel: +82.10.4740.3685 Fax: +82.41.565.6167 email: ewpark@dku.edu
Korean J Med Educ 2013 Sep; 25(3): 229-237.

http://dx.doi.org/10.3946/kjme.2013.25.3.229 pISSN: 2005-727X eISSN: 2005-7288

(C) The Korean Society of Medical Education. All rights reserved. This is an open-access article distributed under the terms of the Creative Commons Attribution Non-Commercial License (http:// creativecommons.org/licenses/by-nc/3.0/), which permits unrestricted non-commercial use, distribution, and reproduction in any medium, provided the original work is properly cited. 


\section{서론}

지역사회중심 일차의료는 환자 개인을 대상으로 한 일차진 료와 지역사회 수준의 건강 증진을 통합하고자 하는 개념으 로서 개개인 환자의 건강 문제 해결뿐만 아니라 환자들이 속 한 특정 지역사회 전체의 건강 문제와 그 문제에 영향을 주는 사회적, 문화적, 환경적 요인들을 파악하고, 지역사회 보건 프 로그램을 실행함으로써 지역사회 건강 수준을 높이며, 지역 사회 조직화를 통하여 지역사회 주민들의 참여를 권장하고자 하는 것이다[1].

의예과 시기는 임상의학 준비 시기로서 기초의학과 연관된 기초과학 과목들뿐만 아니라 인문사회의학 과목들의 병행 교 육이 효율적으로 이루어질 수 있는 시기이다. 일반적으로 인 문사회의학 과목들에는 의료인문학, 의료윤리, 의료와 사회, 의사 직업 전문성 등의 과목이 포함된다. 인문사회의학 과목 중 하나로 지역사회의학 과목은 의과대학이 속해 있는 지역 사회의 인구사회학적 특성을 이해하고, 지역사회진단을 통해 건강위험인자를 분석해보고, 학생들이 할 수 있는 지역사회 프로젝트를 격려할 수 있는 과목이다. 학생들은 지역사회의 학 과목에서 환자에 대한 인격적 이해와 장래의 환자중심적 진료를 효과적으로 수행하기 위한 의사-환자 관계 및 의료커 뮤니케이션 기법을 배울 수 있는 좋은 기회를 얻을 수 있을 것으로 생각된다[2].

의과대학생들에게 임상실습 시기 이전에 지역사회의학을 경험하게 하는 것의 중요성이 강조되어 왔다 $[3,4,5]$. 한국의 의학교육과정에서는 임상실습 이전 시기가 의예과 과정과 임 상실습 전 의학과 혹은 의학전문대학원 과정을 모두 포함한 다고 할 수 있다. Dorman et al. [6]은 체계적 고찰 연구에서 임상실습 전 학년에서 지역사회에서의 임상적 경험에 노출된 학생들이 실습시기에 보다 더 실제적인 경험을 하게 되었으 며, 보건의료체계와 예방의료, 의료전문인들의 역할을 더 잘 이해하게 되었다고 보고하였다. 또한, 지역사회에서 임상적 문제에 조기 노출된 학생들이 일차의료, 혹은 농촌의료에 보 다 더 많이 진출하는 경향을 보였다고 기술하였다.

현재 우리나라 의과대학의 교육 과정 중 인문사회의학 교 육과정이 많이 중요시되고 있으나, 지역사회의학과 관련된
교육은 예방의학이나 의료관리학의 한 영역으로서 매우 미미 한 부분으로 포함되고 있다[7]. 특히 의예과 교육과정에서의 지역사회의학 교육은 단기간의 봉사활동 경험이 주된 것이라 고 할 수 있는데, 이런 단기간의 봉사활동 교육은 의학과 교육 과정과의 연계성이 부족하고, 지역사회진단 및 중재를 위한 단계적 접근을 적용하기가 어려울 것으로 생각된다[8].

단국대학교 의과대학에서는 의예과 2학년 및 의학과 4학년 시기에 지역사회의학 교과목을 개설해 왔다. 의학과 4학년 시 기에는 보건관리 및 의료정책 분야의 이해를 위해 14 시간의 강의 위주의 교육이 이루어져 온 반면에, 의예과 2 학년 시기 에는 의과대학이 속해있는 주변 지역사회를 경험해 보고, 학 생들의 수준에서 가능한 지역사회 보건중재를 위한 활동을 실천해보도록 할 목적으로 30시간의 강의 및 과제실천 교육 이 시행되어져 왔다. 단국대학교 의과대학의 의예과 지역사 회의학 교과목의 목표는 임상의학 준비과정생으로서의 의예 과 학생들로 하여금 지역사회 보건관련 조직망을 이해하고, 지역사회진단에 근거한 건강 요구에 반응하여 지역사회와 협 력하여 건강한 생활습관의 증진과 적정 보건진료를 어떻게 이루어 갈 것인가를 이해하게 하는 것이었다[9].

본 연구의 목적은 2000년부터 2012년까지 13년간 의예과 2학년에서 시행된 지역사회의학 수업 및 실습 시행의 결과를 소개하는 것으로서 의예과 학생들이 제출한 지역사회의학 프 로젝트의 최종 보고서를 내용 분석하여 학생들이 경험한 지 역사회 프로젝트의 대상, 관심주제, 방법들의 특성을 기술해 보고, 학생들이 지역사회 프로젝트를 시행한 후에 느낀 점을 질적 분석하여 지역사회 프로젝트 수행에 대한 학생들의 인 식을 조사해 보는 것이었다.

\section{대상 및 방법}

\section{1. 연구 방법}

2000년부터 2012년까지 의예과 지역사회의학 교육과정(2 학점)이 의예과 2학년을 대상으로 시행되었다. 지역사회의학 강의는 주당 2 시간씩 15 주 동안 이루어졌다. 2 시간의 수업 중 첫 번째 시간에는 4 주 동안 지역사회중심 일차의료의 개념 및 
중요성, 지역사회진단 방법, 지역사회수준에서의 건강증진, 문화가 질병 및 건강에 미치는 영향에 대한 이론 강의가 제공 되었다. 5 주 이후에는 지역사회 전문가들을 초청하여 지역사 회에서 흔한 문제들(지역사회중심 일차의료, 호스피스 진료, 의료와 사회복지, 아동학대, 지역사회 보건소 운영, 지역사회 기반 건강증진 프로그램 운영, 지역사회 간호)에 대한 주제 강의가 제공되었다. 2 시간의 수업 중 두 번째 시간에는 매주 2 편의 지역사회의학과 관련된 주제의 논문들(총 14 편, 7 주간 시행)을 조별로 발표하며 토론하도록 함으로써 지역사회 보 건문제들에 관한 조사를 어떻게 계획할 것이며, 어떻게 보건 자료들을 수집할 것이며, 지역사회 보건요원들과 어떻게 협 동할 것이며, 지역사회 프로젝트 보고서를 어떻게 작성할 것 인가를 이해하게 하였다.

학생들의 지역사회 프로젝트 수행을 위하여, 수업 1차시와 2차시에 한 학기 동안 수행할 주제들을 학생들이 스스로 발제 하여 정하고, 주제별로 소그룹을 구성하여 구체적 실천계획을 세우도록 하였다. 지역사회 프로젝트를 계획하는 과정에서는 지역사회 보건과 관련된 주제를 선정하도록 하였고, 정의된 지 역사회 집단을 대상으로 지역사회 문제를 분석하고, 의예과 학 생들 수준에서 지역사회 건강증진을 위해 실천할 수 있는 활동 들을 계획하게 하였다. 프로젝트의 수행은 구체적으로 다음의 네 단계를 거쳐 준비가 이루어졌다. 첫째로, 학생들이 스스로 제안한 주제들을 수집하여 합의과정을 거쳐 6 7개의 주제를 선택하고 각 주제별로 조를 구성하게 하였고, 둘째로, 학생 소 그룹들이 프로젝트를 수행할 지역을 정의하고 지역의 특성을 조사하도록 하였다. 셋째로, 학생 소그룹들이 지역사회를 방문 하고 학생들이 할 수 있는 수준의 프로젝트를 기획하도록 하였 고, 넷째로, 프로젝트 수행 과정 및 결과, 느낀 점을 조별로 보고하도록 하였다[10]. 학생 소그룹들은 지역사회 프로젝트 수행 중에 담당교수로부터 프로젝트 수행 경과에 대해 모니터 링을 받았으며, 프로젝트 진행의 어려움에 대한 상담을 받았 다. 프로젝트는 한 학기동안 지속적으로 이루어지도록 하였다. 학생 소그룹들은 지역사회 프로젝트를 수행하여 수업 8차시에 프로젝트 중간발표와 14차시에 최종 발표를 하였고, 발표 후 에는 최종 보고서를 제출하였다. 학생들의 평가를 위해 중간 및 기말 지필시험을 시행하였다.

본 연구를 위하여 학생 소그룹들이 한 학기 과정을 마치고
지역사회 프로젝트를 시행하여 제출한 최종 보고서를 내용 분석하였다. 최종 보고서의 분석을 위하여 학생 소그룹들이 프로젝트를 위해 활동한 포트폴리오 자료들을 참고하였으며, 포트폴리오 자료에는 지역사회 프로젝트 계획서, 과제 중간 보고서, 과제 결과자료들이 포함되었다.

\section{2. 분석 방법}

최종 보고서에 기술된 지역사회 프로젝트 대상, 주제, 방법, 결과 등의 내용을 코딩하여 빈도분석을 시행하였고, 만족도 조사에 대한 통계분석도 시행하였다. 통계분석을 위하여 SPSS version 18 (SPSS Inc., Chicago, USA)을 사용하였다.

지역사회 프로젝트 수행에 대한 학생들의 인식을 분석하기 위하여 최종 보고서에 기술된 지역사회의학 프로젝트 과정에 서의 느낀 점에 대하여 질적 내용분석을 시행하였다. 질적 내 용분석은 텍스트 내용의 맥락적 의미에 초점을 맞추어 텍스 트 자료를 분석하는 것으로서 텍스트 자료의 언어적 연관성, 중요성 및 의미의 특성을 기술하는 것이다[11,12]. 본 연구에 서는 최종 보고서에서 학생 소그룹들에게 제출하도록 요구한 지역사회의학 프로젝트 과정에 대해 느낀 점을 텍스트 자료 로 하여 분석을 시행하였다. 질적 내용분석을 위한 연구 설계 및 코딩 범주의 작성을 위하여 질적 연구 전문가 2 인의 감수 를 받았다.

\section{결과}

\section{1. 의예과 학생들의 지역사회 프로젝트 특성}

2000년부터 2012년까지 총 89건의 과제가 570명의 학생들 에 의해 수행되었다. 과제당 학생 수는 평균 6.4명(범위, 3 9 명)이었다.

지역사회 프로젝트 연구 대상별로 연구 과제를 구분해 보 면, 고등학교 학생이 21건으로 가장 많았고, 초등학교 학생 (14건), 미취학 아동(12건), 대학생(10건), 노인(10건), 중학 생(9건), 호스피스 환자(7건), 일반 시민(7건), 외국인 근로자 (5건) 등의 순이었다(Table 1). 79건의 과제에서는 프로젝트 대상이 단일 그룹이었으며, 10 건의 과제에서는 프로젝트 대 
Table 1. Classification of Community Projects by Population

\begin{tabular}{llrc}
\hline \multicolumn{1}{c}{ Classification of population } & Subclassification & No. & $\%$ \\
\hline Students & Primary school & 14 & 14 \\
& Middle school & 9 & 9 \\
& High school & 21 & 21 \\
& College & 10 & 10 \\
Preschool ages & & 12 & 12 \\
Elderly & 10 & 10 \\
Hospice patients & 7 & 7 \\
Migratory workers & 5 & 5 \\
Disabled people & 2 & 2 \\
Industrial workers & 1 & 1 \\
Blood donation managing nurses & 1 & 1 \\
Psychiatric patients & 1 & 1 \\
General citizen & 7 & 7 \\
Total & 100 & 100 \\
\hline
\end{tabular}

Seventy-nine projects had 1 population; 10 projects had multiple populations.

상이 다양한 그룹이었다.

프로젝트 주제별로 과제를 구분해 보면, 총 89건의 과제 중 주제 수는 39개였다. 39 개의 주제 중에서 고등학교 학생 대상 성지식 교육, 중고등학교 학생 대상 금연교육, 호스피스 기관 에서의 노력봉사가 각각 8건으로 가장 많았고, 노인 복지관 노력봉사(6건), 저소득층 미취학아동에 대한 학습 지도(6건), 시설 아동들에 대한 보건교육(4건), 저소득층 초등학생들의 학습지도(3건), 초등학생들에 대한 비만/영양교육(3건), 중학 생들에 대한 성교육(3건), 대학생 건강상태 파악 및 건강교육 (3건), 외국인 근로자 건강실태 조사 및 보건교육(3건), 헌혈 권장 캠페인(3건), 미취학 아동의 비만교육(2건), 대학생들에 대한 절주교육(2건), 외국인 근로자들에 대한 한글교육(2건), 양로원 및 복지관 노인 건강실태조사(2건) 등의 순서로 빈도 가 높았다(Table 2).

이 외에도 어린이집 미취학아동 병원이용/보건교육, 초등 학생 및 부모들에 대한 금연교육, 초등학생 대상 위생교육/질 병예방교육, 초등학생들의 컴퓨터/TV 습관 조사 및 교육, 중 학생들에 대한 폭력예방교육, 고등학생들에 대한 응급처치교 육, 대학생들의 인터넷 중독 실태 조사, 대학 기숙사생들에 대 한 금연교육, 지역보건소 건강걷기대회 도우미, 지역보건소 이동진료 참여, 지역의료원 청소년 건강검진 도우미, 지역사 회 정신보건센터 이용자 만족도 조사, 산업장 재해 실태 조사
등을 시행하였다(Table 2).

프로젝트의 과제수행 방법은 보건교육이 48건으로 가장 많 았고, 복지시설 방문봉사가 18 건이었다. 이 외에도 호스피스 진료 참여(8건), 헌혈 권장 운동 참여(4건), 건강캠페인(2건), 보건소 건강프로그램 참여(2건), 가정 방문조사(1건), 이동진 료 참여(1건), 건강검진 참여(1건), 농촌지역 방문조사(1건), 산업현장 방문조사(1건), 학교양호실 방문조사(1건), 대학캠 퍼스 방문조사(1건) 등으로 이루어졌다. 보건교육의 내용은 성교육, 금연교육, 건강습관교육, 비만예방교육 등이 많았으 며, 이외에도 금주/절주교육, 영양교육, 안전교육, 응급처치 교육, 폭력예방교육 등이 있었다. 일부 소그룹들은 보건교육 을 위하여 비디오교육, 금연카페 등 인터넷클럽 활용, 인형극, 건강캠페인 등을 시행하기도 하였다. 일부 소그룹에서는 호 스피스 진료에 참여하면서 환자 및 가족과의 면담을 시행하 기도 하였고, 환자와의 면담을 녹취하여 발표하기도 하였다. 한 그룹은 저소득층 공동생활가정을 방문하기도 하였다.

학생들은 42건(47.2\%)의 과제에서 사회복지관련 지역사회 자원을 활용하여 과제를 수행하였다. 학생들이 활용한 지역 사회 자원은 보육원 등의 아동보호시설, 호스피스기관, 양로 원 등의 노인복지센터, 외국인 노동자센터 등이 많았으며, 이 외에도 지역 보건소, 정신지체 장애인시설, 어린이집, 여성의 전화, 미혼모시설, 아동보호전문기관, 지역 정신병원, 아동청 
Table 2. Classification of Community Projects by Topic

\begin{tabular}{|c|c|c|c|}
\hline Classification of topics & Subclassification/Clarification & No. & $\%$ \\
\hline \multirow[t]{7}{*}{ Health assessment and health education } & Preschool children & 1 & 1.1 \\
\hline & Children in an orphanage & 4 & 4.6 \\
\hline & Primary school students & 1 & 1.1 \\
\hline & College students & 3 & 3.4 \\
\hline & Elderly in a nursing home & 2 & 2.2 \\
\hline & Migratory workers & 3 & 3.4 \\
\hline & Citizen & 1 & 1.1 \\
\hline \multirow[t]{2}{*}{ Sex education } & Middle school students & 3 & 3.4 \\
\hline & High school students & 8 & 9.2 \\
\hline \multirow[t]{3}{*}{ Smoking cessation education } & Primary school students and parents & 1 & 1.1 \\
\hline & High school students \& middle school students & 8 & 9.0 \\
\hline & College students & 1 & 1.1 \\
\hline \multirow[t]{2}{*}{ Learning guidance of low socioeconomic children } & Preschool children & 6 & 6.8 \\
\hline & Primary school students & 3 & 3.4 \\
\hline Hospice care & & 8 & 9.2 \\
\hline Elderly people care & & 6 & 6.8 \\
\hline \multirow[t]{2}{*}{ Childhood obesity } & Preschool children & 2 & 2.2 \\
\hline & Primary school students & 3 & 3.4 \\
\hline \multirow[t]{2}{*}{ Blood donation } & Status of donation & 1 & 1.1 \\
\hline & Campaign for volunteer donation & 3 & 3.4 \\
\hline Alcohol abuse prevention & College students & 2 & 2.2 \\
\hline Korean language education for migratory workers & & 2 & 2.2 \\
\hline Health and environmental assessment & Rural people & 1 & 1.1 \\
\hline Milk campaign & College students & 1 & 1.1 \\
\hline Internet addiction prevention & College students & 1 & 1.1 \\
\hline First aid education & High school students & 1 & 1.1 \\
\hline Education of cosmetic surgery information & High school female students & 1 & 1.1 \\
\hline Status of school nursing & Middle and high schools & 1 & 1.1 \\
\hline Violence prevention & Middle school students & 1 & 1.1 \\
\hline Computer and TV & Primary school students & 1 & 1.1 \\
\hline Healthy walk campaign of local health canter & & 1 & 1.1 \\
\hline Mobile clinic of local health center & & 1 & 1.1 \\
\hline Health camp of local health care center & & 1 & 1.1 \\
\hline Students health exam in a community hospital & & 1 & 1.1 \\
\hline $\begin{array}{l}\text { Functional assessment of the mentally retarded } \\
\text { people in an institute }\end{array}$ & & 1 & 1.1 \\
\hline Music performance for the disabled people & & 1 & 1.1 \\
\hline $\begin{array}{l}\text { Survey of satisfaction of the users in a community } \\
\text { mental health center }\end{array}$ & & 1 & 1.1 \\
\hline Music therapy for the psychiatric patients & & 1 & 1.1 \\
\hline Assessment of industrial hazard & & 1 & 1.1 \\
\hline Total & & 89 & 100 \\
\hline
\end{tabular}

소년 정신건강센터, 여성의 전화, 헌혈의 집 등이었다. 프로젝트 수행을 위해 학생들은 58건(65.2\%)의 과제에서 설문지를 구성하여 설문조사를 시행하였으며 건강위험인자 들의 유병률 조사 및 행동 변화에 대한 인식도 조사를 시행하
였다. 또한, 48건(53.9\%)의 과제에서 교육자료를 구성하여 교 육을 수행하였다. 


\section{2. 의예과 학생들의 지역사회중심 일차의료 실천 경험에 대한 인식}

지역사회 프로젝트 실천 후에 제출한 최종 보고서에서 학 생들이 기술한 느낌들을 내용 분석하여 지역사회 프로젝트 수행 경험에 대한 학생들의 인식을 조사하였다. 텍스트 자료 의 질적 내용 분석 결과 학생들의 인식 내용은 8가지 범주로 대별할 수 있었다. 8가지 범주의 내용은 1) 의사 전문인으로 서의 정체성, 2) 보건의료체계 및 복지체계에 대한 이해, 3) 봉사하는 삶의 가치 및 만족감, 4) 학생들 간의 유대감 증진, 5) 면담술기의 이해, 6) 예방진료를 위한 의사의 역할, 7) 향 후 진로 선택에 미치는 영향, 8) 임상진료와 관련된 실제성 등 이었다.

의사라는 전문인의 정체성에 대한 기술은 19 건의 보고서에 서 기술되었다. 학생들은 장래의 의사로서의 자신들의 정체 성을 '환자를 이해해 줄 수 있는 따뜻한 마음을 가진 의사', '소 외된 환자들에 대한 사회적 책임을 갖는 의사로 이해하였다. 학생들의 표현 중의 한 예는 다음과 같다. "의사가 되는 일은 좀 더 많은 사람들을 치료하는 것이다. 사람을 치료하는 것은 육체의 질병에만 국한하는 것은 아니고 사람의 마음까지 치 료해야 하는데, 그러기 위해서는 우선 자신부터 따뜻한 마음 을 가져야 할 것이다."

보건의료체계 및 복지체계에 대한 이해는 11 건의 보고서에 서 기술되었다. 학생들은 지역사회 프로젝트를 통하여 공공 의료를 포함한 보건의료체계와 복지체계의 상태를 이해할 수 있었고, 복지의 향상을 위한 국가정책과 사회제도의 변화가 필요하다고 이해하였다. 학생들의 표현 중의 한 예는 다음과 같다. "양로원과 3차 의료기관과의 연계성을 높일 필요가 있 으며, 요양병원과 요양원의 역할이 제대로 자리 잡도록 제도 적 수정이 필요하다."

봉사하는 삶의 가치와 만족감은 9 건의 보고서에서 기술되 었다. 학생들은 지역사회 프로젝트수행에 대해 보람을 느끼 고 있었으며, 앞으로 지속적으로 봉사활동을 할 필요성을 느 꼈다. 학생들의 표현 중의 한 예는 다음과 같다. "봉사활동을 위해 의료커뮤니티를 만들어 돌아가면서 요양원에서 봉사할 필요가 있다. 허름한 양로원 안에서 무료로 할아버지 할머니 들을 친절하게 진찰하는 모습이 멋져 보였다. 지역사회라는
것이 우리 주변에 있다는 것을 인식하는 기회가 되었고, 그곳 에 직접 나가는 것의 기쁨을 알 수 있는 경험이었다. 지속적으 로 특정 대상을 두고 행한 봉사활동은 이번이 처음이라 시간 이 지날수록 봉사를 한다는 생각보다 오히려 그 분들이 우리 에게 너무나도 큰 행복을 주셔서 감사했고, 마음이 벅찬 기분 을 느낄 수 있었다. 진정한 봉사활동은 지속적으로 그분들에 게 관심을 가지는 것임을 알게 되었다."

일부 학생들(7건)은 지역사회 프로젝트 수행을 통해 학생 들 간의 유대감이 증진되었다고 기술하였다. 학생들은 지역 사회 프로젝트를 통해 같은 조의 동료들에 대한 믿음과 친밀 감, 팀워크를 느낌으로써 유대감이 증진되었다고 표현하였고, 조별로 프로젝트를 수행한 것에 대한 자부심을 느꼈다. 학생 들의 표현 중의 한 예는 다음과 같다. "봉사활동 프로젝트를 통해서 얻은 보석은 조원들 간의 믿음과 팀워크이다."

일부 학생들(5건)은 면담술기의 측면에서 환자와의 의사소 통의 어려움, 공감 대화의 필요성, 환자 중심적 대화의 필요성 을 이해하게 되었다고 기술하였다. 또한, 소수의 학생들(3건) 은 예방진료를 위한 의사의 역할로서 성교육, 비만예방, 아동 학대 예방 등을 위한 의사의 역할의 중요성에 관해 기술하였 다. 지역사회 프로젝트 수행 경험이 향후 진로의 선택에 미치 는 영향은 3 건의 보고서에서 기술되었고, 장차 의사가 되어 지역사회에 더 다가갈 수 있는 계기가 되었다는 내용이 포함 되었다. 임상진료와 관련된 실제적 경험에 관해서는 2건의 보 고서에서 기술되었는데, 기술 내용은 의예과 학생들로서의 의료적 봉사활동의 한계에 대해서 언급한 것이었다.

\section{3. 의예과 학생들의 지역사회의학 과정에 대한 만족 도 및 진로 선택에 미치는 영향}

2010년도부터 2012년도까지 3년간 지역사회의학 과정에 참여한 의예과 2학년 133 명의 학생들을 대상으로 지역사회 프로젝트 활동에 대한 만족도와 지역사회의학 과목이 자신의 향후 진로 선택에 영향을 주었는가를 설문조사하였다. 설문 에 참여한 학생들의 평균 연령은 21.3세(표준편차, 1.0)였으 며, 성별 기재를 누락한 3 명의 학생을 제외하여 남학생 95 명 (70.4\%), 여학생 35명(29.6\%)이었다.

조사결과로는 지역사회의학 프로젝트 수행에 대한 학생들 의 만족도는 5점 척도(1점 매우 불만족, 2점 불만족, 3점 보 
통, 4점 만족, 5점 매우 만족)로 평가했을 때 평균 3.9점(표준 편차, 1.0)이었으며, 지역사회 프로젝트 수행 경험이 자신의 향후 진로 선택에 미치는 영향을 조사한 결과는 5점 척도(1점 매우 아니다, 2점 아니다, 3점 보통이다, 4점 그렇다, 5점 매 우 그렇다)로 평가했을 때 평균 3.0점(표준편차, 0.9)이었다. 지역사회의학 과정 중에서 가장 기억에 남는 교육적 경험은 $57.9 \%$ 의 응답자가 소그룹 지역사회 프로젝트의 수행이었다 고 응답하였다.

\section{고찰}

본 연구에서 의예과 학생들이 수행한 지역사회 프로젝트의 주제는 다양했으며, 프로젝트 수행 경험에 대한 인식은 긍정 적이었다. 학생들은 장래의 의사의 역할로서 공감적이며 사 회문제에 책임성이 있는 의료 전문인으로서의 역할을 인식했 으며 지역사회자원 활용의 중요성을 이해했다.

지역사회 프로젝트 과제를 범주별로 구별해 보면 봉사활동 중심 과제, 연구중심 과제, 실습훈련중심 과제로 나눌 수 있다 [13]. 본 연구에서는 학생들의 학습활동의 대부분(77건, 86.5\%)이 봉사활동중심 과제였다. 학생들의 봉사활동중심 과 제들 중 보건교육이 48건(53.9\%)이었다. 연구중심 과제는 11 건(12.4\%)으로서 학생들은 설문조사 혹은 면담조사를 많이 시행하였다. 지역사회 일차의료 클리닉에서의 일차의료 실습 경험은 1 건에서 이루어졌다. 본 연구의 결과에서 $47.2 \%$ 의 학 생들이 사회복지관련 지역사회 자원을 활용하여 사회적 약자 를 대상으로 과제를 수행했으며, 학생들이 시행한 보건교육 주제도 다양하였다.

지역사회에 기반을 둔 의학교육에서 의예과 학생들과 의학 과 학생들의 학습활동은 임상적 다양성에서 차이가 날 수 있 다. 본 연구의 대상 학생들은 지역사회의학 과정을 수료하면 서 실천적 측면에서 소그룹 단위로 자신들의 지역사회를 정 의해 보고, 지역사회 보건과 관련된 조사 및 건강증진을 위한 실천적 과제를 수행한 것으로서, 임상실습 학생들이 지역사 회 의료기관이나 보건 프로그램에서 임상적 경험을 하는 지 역사회 기반 임상실습 교육과 비교할 때 학습내용에서 다른 결과를 보인다고 하겠다[9].
학생들의 지역사회 프로젝트가 효과적으로 수행되기 위해 서는 의과대학과 지역사회 간의 교육, 연구 및 진료를 위한 협 력 관계에 기반하여 의과대학 교수들이 지역사회 교육에 적극 적으로 참여하는 통합적 시스템이 필요하다[14]. 그러나, 본 연구의 대상인 지역사회 프로젝트들은 이러한 기반이 형성되 어 있지 않은 상태에서 지역사회에 기반한 보건요원들의 적극 적인 협동에 의해 이루어지지는 못했으며, 학생들 소그룹들이 독립적으로 과제를 기획하여 수행하고 보고한 것이었다.

의예과 학생들의 지역사회 프로젝트 실천 경험에 대한 인 식도 분석 결과를 학생들의 태도, 지식, 기술 측면에서 고찰해 보면, 태도 측면에서 학생들은 장래의 전문직 의사로서의 정 체성에 대하여 인식하였다. 그 내용은 환자들에 대한 공감적 태도, 소외된 자들을 돌보는 의사의 사회적 역할과 책임, 장래 의사가 되는 것의 자부심, 지역사회 봉사의 만족감과 가치, 보 건교육과 예방진료를 실천하는 의사의 역할의 중요성 등이었 으며, 이런 인식은 의과대학에서의 장래 학습에 대한 동기유 발로 표현되었다. Rooks et al. [15]도 의과대학 1학년 학생 들을 대상으로 한 연구에서 임상실습전 학생들이 지역사회에 서의 일차의료를 경험한 후에 의사의 역할에 대해 자신감을 갖게 되었다고 보고하였다.

또한 학생들은 다른 의료관련 전문인들과의 좋은 관계 형 성의 필요성을 인식하였고, 지역사회 프로젝트를 통하여 동 료들 간의 유대감과 팀워크가 향상되었음을 긍정적으로 인식 하였다. 이는 지역사회에 기반한 소그룹 프로젝트 활동이 리 더십 기술을 배우기 위한 좋은 기회가 될 수 있다는 것을 나타 낸다[13].

지식 측면에서 학생들은 현재의 보건의료체계와 사회복지 체계에 대해 이해하였고, 사회적 약자를 돌보기 위한 지역사 회와 국가의 역할에 대해 이해하였다. 이런 결과는 지역사회 중심 일차의료 실천을 위한 지역사회 보건자원의 활용, 지역 사회 수준에서의 체계적 변화를 위한 보건기획의 필요성에 대한 이해를 나타내고 있는 것이다. 기술 측면에서 학생들은 지역사회 의료기관에서 직접 환자를 면담하는 기회가 적었음 에도 불구하고, 지역사회 프로젝트 경험을 통해 환자와의 의 사소통의 중요성, 공감적 환자중심적 의료커뮤니케이션의 필 요성을 인식하였다.

Copper et al. [16]도 임상실습 전에 의과대학생들로 하여 
금 사회복지 기관에서 지역사회 경험을 하게 한 결과 학생들 이 다학제적 협동의 필요성, 지역사회 내에서의 건강불평등, 환자나 다른 보건전문가들과의 의사소통의 중요성, 보건문제 해결을 위한 지역사회 수준에서의 예방의료적 사회복지적 접 근의 필요성을 인식하게 되었다고 보고하였다.

지역사회에 기반을 둔 의학교육은 의과대학생들이 졸업 후 에 의료 소외지역, 특히 농촌지역에서 일할 수 있도록 기여할 잠재력을 갖는다[6]. 그러나 본 연구에서는 일부 학생들에 대 한 조사에서 지역사회 프로젝트 수행 경험이 자신의 의사로 서의 향후 진로 선택에 영향을 준다는 응답률이 높지 않았다. 인식도 분석에서도 향후 진로선택에 미치는 영향에 대한 언 급에서 학생들은 프로젝트 수행경험을 통해 자신의 장래 전 공분야를 구체적으로 탐색하게 되었다기보다는 장차 의사로 서의 삶에 도움을 줄 것이라는 막연한 인식을 갖는 정도였다. 이러한 결과는 의예과 학생들의 지역사회 경험이 지역사회 환경에서의 임상실습 수준에는 이르지 못했기 때문으로 생각 되며, 또한 학생들이 아직 자신의 장래 진로에 대해 많이 생각 하는 시기가 아닌 것도 원인으로 생각된다.

장래 의사로서 지역사회중심 일차의료를 수행할 수 있는 역량을 갖추기 위하여 의과대학의 교육과정의 일부가 지역사 회에 기반을 두고 구성되는 것은 바람직하다[17]. 일반적으로 지역사회의학 교육이 의과대학 고학년에서 시행되고 있으나, 임상실습 전 시기 중 비교적 시간적 여유가 있는 의예과 2학 년 시기에 지역사회의학을 교육하면, 학생들은 조기에 지역 사회를 경험하고 지역사회 보건문제를 이해할 수 있을 것이 다. 이와 같은 지역사회 노출 경험은 인문의학적 소양을 교육 할 기회를 제공할 것이며, 의예과 교과목들에 대한 학습동기 를 부여할 수 있고, 의학과 시기의 지역사회에서의 임상실습 과 잘 연계될 수 있을 것이다[18,19].

의예과 시기의 지역사회의학 교육에는 지역사회의 흔한 보 건문제나 건강요구의 이해, 지역사회 수준에서의 건강증진 방법의 이해, 활용 가능한 지역사회 자원의 이해가 포함되어 야 한다. 또한, 지역사회 안에서 소그룹 단위로 과제를 실천해 봄으로써 지역사회중심 일차의료의 개념을 경험적으로 이해 할 수 있어야 할 것이다[5,9].

의예과 학생들의 지역사회의학 교육의 향후 발전 방향은 지역사회의 보건 문제 및 건강요구는 항상 변화하고 우선순
위가 달라질 수 있으므로, 지역사회의 요구에 반응하여 지역 사회의학 교육 내용도 매년 달라질 수 있다는 점이다[13]. 이 러한 지역사회의학 교육 기회를 통하여 의과대학과 지역사회 기관들 간의 협력자 관계가 증진될 수 있을 것이며, 결과적으 로 지역사회 보건 문제 해결 및 지역사회 건강증진 실천을 위 한 상승효과가 나타날 수 있을 것이다[4,13,20].

본 연구의 제한점은 수업에 참여한 일부 학생들만을 대상 으로 무기명으로 만족도를 조사함으로써 지역사회 프로젝트 주제 및 실천 방법에 따른 학생들의 만족도의 차이를 비교할 수 없었다는 점이다. 향후 연구 과제로 의예과 시기의 지역사 회의학 교육이 의과대학 졸업 후에 일차의료 및 농촌의료로 의 진출에 의미 있는 영향을 줄 수 있는지에 대한 전향적 연구 와 지역사회의학 교육이 진로 선택에 미치는 영향을 의예과 와 의학과 학생들 간에 비교하는 연구가 가능할 것이다.

Acknowledgements: None.

Funding: This research was done by the support of 2012 Dankook University Research Fund.

Conflicts of interest: None.

\section{REFERENCES}

1. Nutting PA, ed. Community-oriented primary care: from principle to practice. Albuquerque, USA: University of New Mexico Press; 1990.

2. Bauman KA, Magill MK. Introducing communityoriented primary care to first-year medical students. J Med Educ 1986; 61(9 Pt 1): 762-763.

3. Kristina TN, Majoor GD, van der Vleuten CP. Comparison of outcomes of a community-based education programme executed with and without active community involvement. Med Educ 2006; 40: 798-806.

4. Carlton B, Weston WD. The need for a communitybased, integrated system of care. Acad Med 2000; 75: 721-723. 
5. Whitcomb ME. What community-based education can teach tomorrow's doctors. Acad Med 2005; 80: 315-316.

6. Dornan T, Littlewood S, Margolis SA, Scherpbier A, Spencer J, Ypinazar V. How can experience in clinical and community settings contribute to early medical education? A BEME systematic review. Med Teach 2006; 28: 3-18.

7. An JH, Kwon I, Lee SN, Han JJ, Jeong JE. Study on the medical humanities and social sciences curriculum in Korean medical school: current teaching status and learning subjects. Korean J Med Educ 2008; 20: 133144 .

8. Kim SY, Choi YS, Kim DG, Kim SM, Kim SH, Ahn D, Lee Y. The educational effect of pre-medical curriculum for a service learning program. J Korean Acad Fam Med 2008; 29: 867-871.

9. Chastonay P, Rougemont A, Vu NV. A community-skills program in a preclinical curriculum. Acad Med 1997; 72: 435-436.

10. Bonafede K, Reed VA, Pipas CF. Self-directed community health assessment projects in a required family medicine clerkship: an effective way to teach communityoriented primary care. Fam Med 2009; 41: 701-707.

11. Hsieh HF, Shannon SE. Three approaches to qualitative content analysis. Qual Health Res 2005; 15: 1277-1288.

12. Graneheim UH, Lundman B. Qualitative content analysis in nursing research: concepts, procedures and measures to achieve trustworthiness. Nurse Educ Today 2004; 24 :
105- 112 .

13. Magzoub ME, Schmidt HG. A taxonomy of communitybased medical education. Acad Med 2000; 75: 699-707.

14. Kristina TN, Majoor GD, van der Vleuten CP. Defining generic objectives for community-based education in undergraduate medical programmes. Med Educ 2004; 38: 510-521.

15. Rooks L, Watson RT, Harris JO. A primary care preceptorship for first-year medical students coordinated by an Area Health Education Center program: a six-year review. Acad Med 2001; 76: 489-492.

16. Cooper HC, Gibbs TJ, Brown L. Community-orientated medical education: extending the boundaries. Med Teach 2001; 23: 295-299.

17. O'Toole TP, Kathuria N, Mishra M, Schukart D. Teaching professionalism within a community context: perspectives from a national demonstration project. Acad Med 2005; 80: 339-343.

18. Ahn DS, Lee YM, Yoon MS. Evaluation of premedical curriculum at Korea University. Korean J Med Educ 2000; 12: 207-214.

19. Baek WK, Chun KH. A research about students' satisfaction on premedical curriculum. Keimyung Med J 2009; 28(Suppl): S27-S33.

20. Kim JB, Lee Y, Joo EK, Chun KH. Community-oriented primary care: preparing physicians for the future in the United States. Korean J Med Educ 2000; 12: 329-341. 